\title{
Los titulares en los principales cibermedios europeos: más funcionales y menos conceptuales ${ }^{1}$
}

\author{
Berta GARCÍA OrosA \\ Universidad de Santiago de Compostela \\ bertago@gmail.com \\ Xosé López García \\ Universidad de Santiago de Compostela \\ Xose.lopez@usc.es
}

Recibido: 6 de marzo de 2014

Aceptado: 9 de septiembre de 2014

\begin{abstract}
Resumen
Los titulares en los cibermedios continúan siendo el principal medio tractor y atractor de audiencia, pero sus características y funciones se adaptaron a un nuevo entorno de producción y recepción en la red. El artículo ofrece una radiografía de los titulares de los principales cibermedios de España, Gran Bretaña, Francia, Italia y Portugal (The Times, Le Monde, Corriere della Sera, Journal de noticias, El País) a través del análisis de contenido de la portada, de las noticias, de los metadatos y de los elaborados para las redes sociales. Con algunos cambios de diseño y contenido, la estrategia de titular combina las funciones tradicionales con la orientación cada vez mayor hacia los buscadores y las redes sociales como focos de entrada de los usuarios desde otros lugares de la red.
\end{abstract}

Palabras clave: titular, ciberperiodismo, periodismo digital, periodismo europeo, posicionamiento.

\section{Headlines in major European digital media in Europe: more functional than conceptual}

\begin{abstract}
Headlines of European online media still are the main appealing focus of audience. Nevertheless, its properties and functions have had to adapt to an on line context of production and reception. This paper presents an overview of headlines in Europeans online media in Spain, Britain, France, Italy and Portugal (The Times, Le Monde, Corriere della Sera, Journal de noticias, El País) through a content analysis of front page, news page, metadata and the social networks. By slightly changing design and content, the traditional strategy of headline mixes traditional functions with a compulsory adjustment to searching engines and social networks as a gateway for more news users and traffic from other websites.
\end{abstract}

Keywords: headlines, digital media, european journalism, Search Engine Optimization.

\section{Referencia normalizada}

GARCÍA OROSA, Berta y LÓPEZ GARCÍA, Xosé (2015): "Los titulares en los principales cibermedios europeos: más funcionales y menos conceptuales". Estudios sobre el Mensaje Periodístico. Vol. 21, Núm. 2 (julio-diciembre), págs.: 833-847. Madrid, Servicio de Publicaciones de la Universidad Complutense.

Sumario: 1. Introducción. 2. Marco teórico. 3. Metodología. 4. Análisis de datos. Transformaciones en diseño y contenido para nuevos roles. 5. Conclusiones. 6. Referencias bibliográficas.

1 La investigación que ha dado lugar a este artículo ha sido desarrollada en el marco del proyecto de investigación financiado por el Ministerio de Economía y Competitividad "Innovación y desarrollo de los cibermedios en España. Arquitectura de la interactividad periodística en dispositivos múltiples: formatos de información, conversación y servicios" del que forman parte los dos autores del texto [Referencia: CSO2012-38467-C03-03] 


\section{Introducción}

Pese a ser un elemento ausente en los primeros pasos del periodismo (Fontcuberta, 1993:117), el titular ha sabido adaptarse en los últimos años a los cambios de contenido y forma sufridos por el sistema mediático. Desde comienzos del siglo XX, ha sido la primera aproximación del lector a la información que no sólo permitía obtener un conocimiento inicial sobre la misma sino también orientar al receptor sobre si le interesaba su lectura o abandonarla. Desde entonces, han ido incrementando su presencia y funciones en todos los medios de comunicación y soportes.

La importancia de los titulares en medios impresos y, a continuación en los audiovisuales, no dejó de crecer en las últimas décadas. Como indica María José Pou Amérigo (2004: 239), "Los titulares son a cada texto periodístico lo que la portada a todo un diario". Surgió con una única finalidad: atrapar al lector, distraerlo de otros quehaceres, seducirlo hasta dejarlo satisfecho con la información que le transmitía, o bien hasta despertarle la curiosidad que le hace cada día leer la noticia que encabeza (López Hidalgo, 2001: 18), pero sus objetivos se fueron multiplicando con el paso de los años.

La llegada de los medios de comunicación a internet supone un nuevo reto para los titulares que, además de continuar con las múltiples funciones adquiridas en los últimos años, deben adaptar su estilo y contenido al nuevo soporte. La multimedialidad, la ruptura de la secuencialidad a través del hipertexto y el hipermedia, la ruptura de la periodicidad, la interactividad o la legibilidad (Díaz Noci, 2002) son características del nuevo entorno con las que los titulares deben convivir.

Además, los espacios on line por los que circula el titular y los contextos en los que son recibidos y decodificados por el receptor se multiplican reforzando aspectos básicos de la preceptiva periodística tradicional como la necesidad de que el título tenga sentido propio y asumiendo otros nuevos. La deslocalización espacio-temporal de la lectura que permite internet obliga a los editores a un nuevo esfuerzo por buscar redacciones complejas que permitan una correcta eficacia comunicativa tanto en la propia web del medio de comunicación como en las redes sociales o los dispositivos móviles.

Los titulares se multiplican en la red y sus roles crecen y se diversifican llegando a constituir en los últimos años secciones propias en las portadas de los principales ciberdiarios europeos. Sin embargo, este incremento de presencia y funciones de los titulares en los medios digitales no se ha visto acompañada en los últimos años con investigaciones en el ámbito del periodismo que permitan registrar la evolución de las mismas. Antes bien, el titular, salvo grandes excepciones de monográficos y artículos publicados sobre el mismo (Gómez Mompart, 1987; López Hidalgo, 2001), ha quedado relegado a una variable más de estudios realizados sobre la agenda mediática, redacción periodística o recepción, entre otros. Por este motivo, consideramos pertinente la investigación cuyos primeros resultados se presentan en este artículo sobre la evolución de este elemento de la noticia en la web. Se pretende realizar una radiografía de los titulares en los diarios en los cibermedios europeos que permita comprobar el alcance de su desarrollo, de los nuevos y viejos roles y dilucidar un camino que todavía no hizo más que empezar hacia el que, creemos, constituye una nueva etapa del titular periodístico. 


\section{Nuevos roles para un titular con mayor presencia}

El titular fue tratado desde un inicio por la preceptiva periodística como uno de los principales elementos de la noticia que debía ofrecer al lector no sólo un resumen de lo más importante de la misma sino también llamar la atención e incitar a continuar la lectura. Los diferentes elementos de la titulación adquirían la responsabilidad de ser el escaparate o presentación de la información ante el lector. En la etapa del periodismo ideológico el sistema de titulación de las escasas unidades redaccionales informativas que entonces se publicaban seguían las pautas estilísticas empleadas para clasificar los capítulos de un libro y eran títulos lacónicos y carentes de acción, rótulos que tenían el objetivo de llamar la atención del lector y ordenar Casasús (1988, p. 124).

Sus funciones fueron, de esta manera, evolucionando desde la simplemente indicativa hasta la expresiva o apelativa. Si bien nació con las funciones de identificar la noticia como tal, anunciar el tema y resumir u ofrecer los datos más relevantes de la noticia, en la actualidad no son menos importantes las funciones interpretativa, la explicativa del acontecer y las relacionadas con las acciones informativas desde el punto de vista del medio aunque no siempre se consigue con éxito (Gómez Mompart, 1982: 35). Desde la guerra de Cuba de 1890 y, sobre todo, desde la Primera Guerra Mundial (Fontcuberta, 1993), los investigadores advirtieron progresivamente de la importancia del titular y, al mismo tiempo, aumentaron sus responsabilidades y roles la responsabilidad y los roles que se les iban adjudicando. Con los titulares el periodismo trata por lo pronto de persuadirnos de que pasan cosas interesantes (Gomis, 1991: 31). En palabras de Alarcos Llorach, los titulares periodísticos cumplen tres funciones: a) distinguir los diversos titulares del mismo contexto; b) adecuar las referencias reales de titulares y noticias y c) despertar el interés del lector (Alarcos Llorach, 1977: 127). Francisco Sánchez adopta la clasificación de Charles Grivel cuando formula tres funciones de los títulos literarios: identificar la obra; designar su contenido y destacarlo (Fontcuberta, 1993: 118-119).

Ya en el siglo XXI, los estudios sobre los titulares están vinculados a los nuevos medios de comunicación y mantienen las funciones tradicionales, aunque se subraya especialmente la de interpretar el acontecimiento periodístico desde el punto de vista del medio: a) destacar los aspectos más importantes de la noticia; b) llamar la atención del lector para conseguir que siga leyendo la información, c) mostrar la interpretación que el medio hace de los acontecimientos (Pou Amérigo, 2004: 239- 257). En este sentido, Dolors Palau (2013: 837) resalta en una investigación reciente cómo "La formulación sintética de los titulares y su condición de reclamo privilegia la presencia de operadores pragmaestilísticos léxicos, desde sustantivos o verbos a adjetivos -destinados especialmente a identificar los hechos o a los agentes que intervienen-, en los que la interpretación se evidencia de forma más explícita y decantada".

Debido a las propias características estilísticas del titular, un texto muy breve, primer contacto del receptor con la noticia, que requiere un gran esfuerzo de concisión por parte del periodista, la tecnología se erige en uno de los más factores más influyentes en su forma y contenido desde el inicio. Los investigadores coinciden en resaltar la importancia e influencia de los avances tecnológicos, incluso de forma más profunda que en otros elementos de la información. Ya en la década de los 90 del siglo 
pasado, José Manuel Zorrilla (1996: 377) indicaba en los resultados de una encuesta realizada a los responsables de la titulación de los principales periódicos españoles que la gran mayoría de los entrevistados se sentían condicionados por las reglas que impone "la moderna tecnología de las artes gráficas, en el ámbito de la tipografía, la confección y la informática, cuando titulan".

Desde la primera década del siglo XXI, los cibermedios han dejado definitivamente de ser un fenómeno marginal en las empresas de comunicación y forman ya parte esencial del engranaje mediático (Masip, 2010), en los que titulares, portadas y elementos multimedia destinados sobre todo a temas políticos no dejan de crecer (Odriozola, 2012) Algunos autores comparan esta revolución con la que hace cinco siglos produjo en el mundo occidental la imprenta, y la consideran imparable, si bien no ha hecho más que comenzar (Díaz Noci, 2010: 561).

La literatura coincide en otorgarle una gran importancia al titular dentro de los diferentes espacios de los nuevos medios por sus propias características. En primer lugar porque "Desde finales de los años 1990, la prensa en internet apostó fuertemente por la información de última hora. Esta apuesta se basaba sobre todo en dos motivos: ayudaba a mitigar el efecto de canibalización entre la versión impresa y la digital al distinguir sus respectivos contenidos, $\mathrm{y}$, en segundo lugar, incitaba al lector a visitar el cibermedio varias veces al día, con lo que el tráfico se multiplicaba" (Salaverría, 2005: 151).

En este contexto el titular, como elemento que puede resumir en poco tiempo y espacio los últimos datos conocidos sobre el hecho informativo en un contexto de cambio de periodicidad (Edo, 2003: 76) multiplica su importancia y, al mismo tiempo, su presencia en los medios de comunicación tal y como había ocurrido anteriormente con la llegada de los medios audiovisuales. Además de su importancia como avance informativo de la "última hora", la literatura científica destaca la que fue principal característica del titular en la red: el enlace. Como señala Salaverría (2005), si bien la noticia tradicional se caracterizaba por recurrir a una titulación informativa que resume y destaca el aspecto más relevante de la información, en los cibermedios se ha generalizado el empleo del titular como lugar para el anclaje de origen de los hipervínculos. Y los avances registrados en los últimos años han sido espectaculares. No debemos olvidar que, al principio, en 1999, los titulares eran un documento de texto sin enlace a la web (Pou Amérigo, 2001: 154) con lo que se obligaba al lector a acudir a la página buscando la noticia que había suscitado su interés y que en algunos periódicos como El País todavía se indicaba la dirección del página debajo del titular.

La actualización y la hipertextualidad se destacan así como elementos que pueden alentar la importancia del titular y, en menor medida, la multimedialidad y la interactividad que, pese a convertirse en uno de los principales atractivos de la red como se resalta en monográficos como el recientemente publicado "New media, audience and emotional connectivity" (Sociedad de la información, 2013), no son trabajados explícitamente en el caso del titular.

No obstante, el titular incrementó su espacio en los medios de comunicación ocupando no sólo el lugar inicial de la noticia, sino siendo en ocasiones, como los informativos de radio y televisión casi una sección autónoma que abre los espacios informativos. 
La llegada de los medios electrónicos supuso un nuevo cambio no sólo en el canal de transmisión sino también en el contenido informativo de los medios. La creación de un nuevo contexto, provoca transformaciones relevantes en el formato y el contenido de la información. Y el titular, como elemento fundamental de la misma no está ausente a esta nueva realidad y podría tener que adaptarse a la lectura en diferentes contextos, al sistema de documentación y recuperación de información propuesto por la red, así como a las posibilidades de lectura en diferentes contextos geográficos y culturales y de traducción inmediata. Entre los posibles cambios está la opción de traducción rápida de la web que puede llevar a seguir consejos como el indicado por Lara Cid "la omisión de los artículos definidos e indefinidos y el uso de tiempos verbales presentes para expresar las ideas de todos los tiempos verbales. Estas categorías comparten no sólo la mayor contribución de ejemplos en el análisis, sino que también patrones similares para su enunciación, lo que puede contribuir a una mejor traducción de titulares. Además, se recomienda poner atención en la enunciación de los sujetos en inglés, para que el sujeto en español pueda quedar tácito. En estos casos, el sujeto puede ser omitido debido a la escasa relevancia que tiene o porque el agente cumple una función que ya forma parte de un saber compartido (Lara Cid, 2011: 44-45)".

En definitiva, el titular no sólo es el género leído por la mayoría de los lectores y, en ocasiones, el único leído (Hidalgo, 2001: 16), sino también uno de los grandes valores emergentes de los medios de comunicación digitales a los que les ofrece diversas posibilidades para continuar cumpliendo sus funciones tradicionales y asumiendo los nuevos roles que internet permite. Por este motivo, se considera necesaria en el momento actual la realización de una radiografía de los titulares en portada en los principales diarios europeos asumiendo el nuevo entorno como un factor de modificación más que permita conocer la realidad de uno de los géneros periodísticos de mayor dificultad en su producción y de mayor relevancia para el receptor.

\section{Metodología}

El titular es el primer foco que tiene el lector del contenido del medio pero, sobre todo, en diseño y formato. Por lo tanto, tendría que ser uno de los más permeables a los cambios y, en principio, un síntoma de lo que podemos encontrar dentro del mismo. Por este motivo, el objetivo principal de la investigación es realizar una radiografía de los titulares en los principales cibermedios en Europa como principal elemento informativo y de reclamo tras su adaptación a la red. A partir de éste se elaboraron los siguientes objetivos secundarios:

a) Analizar la innovación tecnológica en los titulares, entendiendo esta como las modificaciones registradas por el uso de la tecnología en forma o en contenido.

b) Estudiar las principales funciones de los titulares en los cibermedios europeos.

c) Analizar la estructura formal del titular.

d) Examinar las características de contenido de los elementos de la titulación.

e) Analizar la adaptación los titulares a los buscadores y nuevos contextos de lectura de la información en la red. 
La investigación partió de las siguientes hipótesis:

1. El titular incrementa su presencia y relevancia en las portadas de los ciberdiarios europeos.

2. La función principal del titular continúa siendo informativa, aunque se asumen otras propias de la red como la transmisión a través de redes sociales, la personalización de la información o el fácil acceso del lector a través de los buscadores.

3. Existe una tendencia a la claridad y nitidez en los diseños de las portadas que provoca la eliminación de la mayoría de los elementos tradicionales de la titulación.

La técnica utilizada para el procesamiento de los datos fue el análisis de contenido de cinco elementos de los periódicos: los titulares de portada, los titulares de las noticias correspondientes de los medios trabajados, las etiquetas y palabras clave y el estudio de los metadatos de las mismas. Se seleccionaron medios de los cinco países incluidos en el estudio que cumplieran las siguientes características fundamentales: 1) estar producido por una empresa periodística de referencia en Europa que hubiese publicado un periódico en papel y, posteriormente, trasladara el medio a la red; y 2) ser el de mayor difusión en su ámbito. Se eligieron los países colindantes con España: el diario El País de España; The Times de Gran Bretaña; Le Monde de Francia; Jornal de Noticias de Portugal y Corriere della Sera de Italia. Se trabajó con los titulares publicados por estos medios de comunicación durante una semana seleccionada aleatoriamente para el registro de datos -20 a 27 de febrero, ambos incluidos- con una ficha de análisis que recogía los siguientes apartados: información general sobre el medio; características generales del titular de portada; características generales del titular de interior; adaptación a la red en ambos casos; análisis de las etiquetas, palabras clave y los metadatos de la noticia.

\section{Análisis de datos. Transformaciones en diseño y contenido para nuevos roles}

Las funciones tradicionales de los titulares en los diarios impresos, informar, atraer al lector y jerarquizar la noticia, se mantienen y conviven con otras propias de la red. El titular adquiere una gran importancia dentro de las portadas de los cibermedios como indicador del contenido de la noticia y, sobre todo, como guía de los posibles itinerarios de lectura ofrecidos al receptor a través de los diferentes apartados que ofrece la noticia. El País pero, sobre todo, Jornal de Noticias y The Times, suelen desarrollar brevemente la noticia a través de un lead o incluso una entradilla en la primera página del periódico, pero, en el caso de Le Monde y Corrieri della Sera el titular consigue mayor protagonismo y se convierte, conjuntamente con la fotografía, en el referente para el receptor de la noticia en la primera página. Además de la informativa -y, en ocasiones, apelativa-, el titular en los cibermedios cumple otras tres funciones externas a la propia página dónde se ubica: a) facilitar su localización a través de los buscadores digitales; b) diseñar un itinerario hipertextual que facilite e incite a la lectura personalizada de aquellos aspectos del texto que pueda interesar a cada uno de los receptores y c) favorecer un buen posicionamiento de la información en la red. 
Para la consecución de los nuevos roles, los medios de comunicación innovan formas y contenidos que permitan equilibrar el objetivo de eficacia comunicativa, la competencia con los viejos y nuevos medios y la adaptación al nuevo entorno y diferentes plataformas de difusión del mensaje. Veamos brevemente cada uno de ellos.

En cuanto al contenido y tal como se puede apreciar en el gráfico 1, la mayoría de los titulares analizados continúan siendo informativos y permiten identificar la unidad de una acción de forma singular y centrar el tema principal de la noticia; no obstante, adaptan su tamaño y palabras a la red, además de los diferentes elementos con los que trabajan. También en su gran mayoría, describen la acción, pero se tiene en cuenta el tiempo y el espacio digital evitando informaciones comprometidas que hagan referencias horarias o temporales que puedan dificultar su recepción en latitudes temporales diferentes y, en cambio, se prima la exigencia que ya tenían los titulares en los medios de comunicación escritos de tener sentido en sí mismo porque en el caso de la red su recepción no siempre se ejecuta en el contexto de la página que lo recontextualiza y aporta nuevos significados (frases con sentido completo, referencias espaciales, etc.).

En algunas ocasiones, se opta por titulares expresivos incluso en la noticia principal de la portada como en el caso de los siguientes titulares: "The silent epidemic hitting top girls'schools" (The Times, 22 de febrero de 2014) y “Théorie du genre', dix liens pour comprendre" (Le Monde, 26 de febrero de 2014).

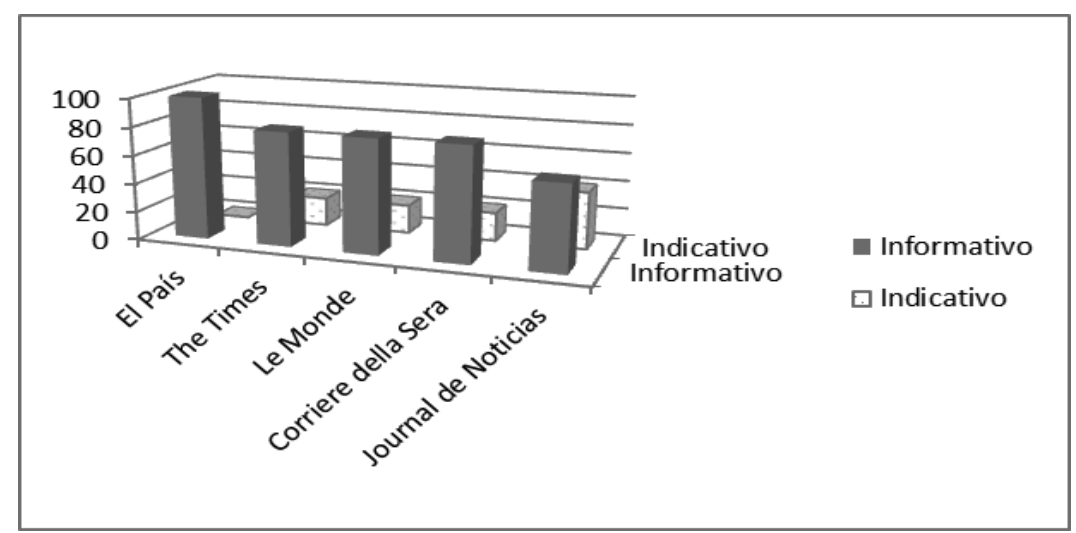

Gráfico 1. Principal título de la portada. Tipología. Fuente: elaboración propia

Como consecuencia de las características de la red, se tiende a titulares que primen la actualidad "último segundo" de la noticia que lleva a algunos medios a mover de sitio los textos a lo largo de las horas para dar sensación de actualidad. Por lo tanto, se busca un titular informativo, sin ambigüedades y con palabras clave que piensen también en los diferentes contextos en los que se va a leer (redes sociales, dispositivos móviles, etc) pero, sobre todo, en la posibilidad de localizar a través de los buscadores. Y esta es una de las claves de los cambios de titulares en la red: la adaptación de la sintaxis y la semántica a las necesidades de los buscadores y de los posicionamientos web. Como podemos observar en la tabla, los medios digitales con este fin ti- 
tulan hasta tres veces de forma diferente, aunque la tendencia en los medios analizados es a que los tres espacios estudiados (portada, página de la noticia y twitter) compartan un mismo título con pequeñas modificaciones. Cuando existen cambios, el título de la página interior suele utilizar palabras comunes como "entregar" en lugar de "inutilizar" en el titular del viernes 21 de febrero de 2014 de El País que podemos leer a continuación: "ETA escenifica antes los verificadores la inutilización de parte de su arsenal" (portada) y "ETA escenifica antes los verificadores la entrega de parte del arsenal" (interior). En todo caso, el de la página interior es el que, además de buscadores y RSS, se transmite a través de twitter, sin añadir etiquetas más llamativas. Este segundo titular contiene más palabras claves que suelen ser nombres propios, de lugares que describen específicamente el tema de la noticia pero que al mismo tiempo la unen con otros grandes temas de actualidad facilitando la búsqueda por parte del lector y el acceso a las mismas. Tanto las palabras clave como las etiquetas tienden a ser precisas e informativas y estar incluidas al principio del titular. La adaptación a las nuevas plataformas se detecta, sobre todo, en la brevedad (sin superar los 100 caracteres y, en la mayoría de los casos los 50) para una correcta recepción en los dispositivos móviles y para las redes sociales, con el valor añadido de dejar caracteres libres para ser retuiteado por los otros usuarios. Entre las estrategias del titular está el control de su longitud de tal forma que permita la difusión vía twitter y facilite su legibilidad en redes sociales como Facebook o Google+, en dipositivos móviles y en lectores de RSS. Se descartan, en general, la ironía, la polisemia, los dobles sentidos, y otras figuras retóricas que puedan dificultar la decodificación en los nuevos contextos.

Tabla 1. Título principal de portada. Martes 25 de febrero 2014 (17.45 h).

Elaboración propia

\begin{tabular}{|c|c|c|c|c|c|c|}
\hline Medio & Título portada & Título página interior & Metadatos título & Titular twitter & \begin{tabular}{|c|} 
Etiquetas \\
\end{tabular} & \begin{tabular}{|l|} 
Palabras clave \\
\end{tabular} \\
\hline El País & $\begin{array}{l}\text { Rubalcaba: "Las mujeres } \\
\text { no le necesitan de tutor. } \\
\text { Retire la ley del aborto" }\end{array}$ & $\begin{array}{l}\text { Directo: Rajoy, a } \\
\text { Rubalcaba: "Le trae sin } \\
\text { cuidado el fracaso } \\
\text { escolar" }\end{array}$ & $\begin{array}{l}\text { Directo: Rajoy, a } \\
\text { Rubalcaba: "Le trae sin } \\
\text { cuidado el fracaso } \\
\text { escolar }\end{array}$ & $\begin{array}{l}\text { Directo | Rajoy, a } \\
\text { Rubalcaba: "Le trae sin } \\
\text { cuidado el fracaso } \\
\text { escolar }\end{array}$ & \begin{tabular}{|l} 
Debate estado nación \\
2014 \\
Mariano Rajoy \\
Alfredo Pérez \\
Rubalcaba \\
X Legislatura España \\
Debate estado nación \\
Congreso Diputados \\
Debates parlamentarios
\end{tabular} & $\begin{array}{l}\text { Directo, rajoy, rubalcaba } \\
\text { le, traer, cuidado, fracaso, } \\
\text { escolar, presidente, } \\
\text { contraatacar, discurso, } \\
\text { líder, oposición, hoy, } \\
\text { hablar, recesión, psoe, } \\
\text { arrancar, país, vivir, } \\
\text { millón, español, peor, } \\
\text { cosa, estar, asegurar }\end{array}$ \\
\hline The Times & $\begin{array}{l}\text { Tory MP and wife in fraud } \\
\text { quiz 'endure horror story' }\end{array}$ & $\begin{array}{l}\text { Tory MP and wife in } \\
\text { fraud quiz 'endure } \\
\text { horror story' }\end{array}$ & $\begin{array}{l}\text { Tory MP Peter Bone } \\
\text { and wife in fraud quiz } \\
\text { 'endure horror story }\end{array}$ & $\begin{array}{l}\text { Tory MP Peter Bone } \\
\text { and wife in fraud quiz } \\
\text { "endure horror story } \\
\end{array}$ & & \\
\hline Le Monde & $\begin{array}{l}\text { «Il faut mettre un terme à } \\
\text { la guerre ukraino- } \\
\text { ukrainienne " }\end{array}$ & $\begin{array}{l}\text { "Il faut mettre un terme } \\
\text { à la guerre ukraino- } \\
\text { ukrainienne » }\end{array}$ & $\begin{array}{l}\text { " Il faut mettre un terme } \\
\text { à la guerre ukraino- } \\
\text { ukrainienne » }\end{array}$ & $\begin{array}{l}\text { "Il faut mettre un terme } \\
\text { à la guerre ukraino- } \\
\text { ukrainienne» }\end{array}$ & & \\
\hline $\begin{array}{l}\text { Jornal de } \\
\text { Noticias }\end{array}$ & $\begin{array}{l}\text { Condenado a } 24 \text { anos por } \\
\text { matar, desmembrar e } \\
\text { queimar vítima } \\
\end{array}$ & $\begin{array}{l}\text { Condenado a } 24 \text { anos } \\
\text { por matar, desmembrar } \\
\text { e queimar vítima }\end{array}$ & \begin{tabular}{|l|} 
Condenado a 24 anos \\
por matar, desmembrar \\
e queimar vítima \\
\end{tabular} & $\begin{array}{l}\text { Condenado a } 24 \text { anos } \\
\text { por matar, desmembrar } \\
\text { e queimar vítima }\end{array}$ & Segurança & $\begin{array}{l}\text { Segurança } \\
\text { segurança }\end{array}$ \\
\hline $\begin{array}{l}\text { Corriere della } \\
\text { Sera }\end{array}$ & $\begin{array}{l}\text { Renzi: «Abbiamo } \\
\text { un'unica chance» }\end{array}$ & $\begin{array}{l}\text { Renzi alla Camera: } \\
\text { questo governo non ha } \\
\text { alibi } \\
\text { «Rivoluzionare le } \\
\text { norme sul lavoro» }\end{array}$ & & & & $\begin{array}{l}\text { Politica } \\
\text { Tweet } \\
\text { Renzi } \\
\text { Fiducia } \\
\text { camera } \\
\end{array}$ \\
\hline
\end{tabular}

En los cibermedios el título obtiene el máximo protagonismo al desaparecer o reducir su presencia elementos con funciones específicas en los diarios impresos que pierden su rol en un discurso hipertextual como la entradilla o el antetítulo. De este modo, en el intento de conseguir un diseño más nítido, primar la legibilidad y la co- 
municación directa y eficaz al lector de uno o dos aspectos de la información, los títulos se quedan prácticamente sólos en la mayoría de los medios europeos. Así, el título es habitualmente de carácter informativo, continúa utilizando la caja baja y negrita y siempre es un enlace hacia la noticia de páginas interiores. Habitualmente mantiene el negro como color principal, excepto en Le Monde y Jornal de Noticias que figuran en azul. Sin duda, la tendencia lo lleva a constituirse el elemento más destacado del titular y se está convirtiendo, al mismo tiempo que la información multimedia en los casi únicos elementos de primera página.

Los otros dos elementos que se mantienen y aumentan su importancia son los subtítulos y los cintillos. En el caso del primero, se mantiene y potencian los subtítulos que conducen al lector hacia otros puntos complementarios de la noticia principal de contexto, de desarrollo o de documentos multimedia. Se ha elegido mantener el nombre utilizado por la preceptiva periodística pero se considera que la función del mismo, en este caso casi siempre conjunto de subtítulos se modificó, ya que no sólo ofrecen información secundaria que apoya al título, sino que también se utiliza para titular elementos multimedia o aspectos complementarios o paralelos al tema principal de la información trabajado por el titular.

En el caso del cintillo, pese a que en un inicio se pronosticó su desaparición ya que su función principal en la prensa escrita era la unión de noticias diferentes bajo un mismo tema, el cintillo resurge con fuerza en medios como Corrieri della Sera ("Inquinamento", "L'Inchiesta", "Ucraina, ricercato L'ex premier") y prácticamente desaparece en The Times y Le Monde. Se convierte en un elemento muy breve y descriptivo, utilizando siempre las palabras clave y en algunos medios incluso aparece en prácticamente todas las noticias de la portada a modo de titulillo.

Otro de los elementos tradicionales del titular en los medios impresos, el ladillo, desaparece en la mayoría de los medios de comunicación pero, en los que se mantiene adquiere más fuerza. Sigue siendo un titular intermedio o pequeños títulos que se coloca dentro del texto para dividir informaciones extensas en partes más reducidas y para atraer o reavivar la atención del lector sobre algún aspecto nuevo al hecho que se cuenta pero, en la red, sobre todo el ladillo funciona como un enlace a textos propios del medio como ocurre, por ejemplo, en las principales noticias de Le Monde.

Mientras tanto, el antetítulo casi desapareció en los ciberdiarios y el sumario se transforma en varios sumarios o índices que conducen al lector a las diferentes partes de la noticia pero sólo en el caso de la principal o las dos principales como ocurre en el caso de Le Monde. Excepcional también es el uso de la entradilla. Su uso es muy escaso pero ocurre en ocasiones como El País. En esta ocasión era la descripción que figuraba en los metadatos a primera hora de la mañana y que tres horas más tarde se convirtió en la entradilla de la portada. 


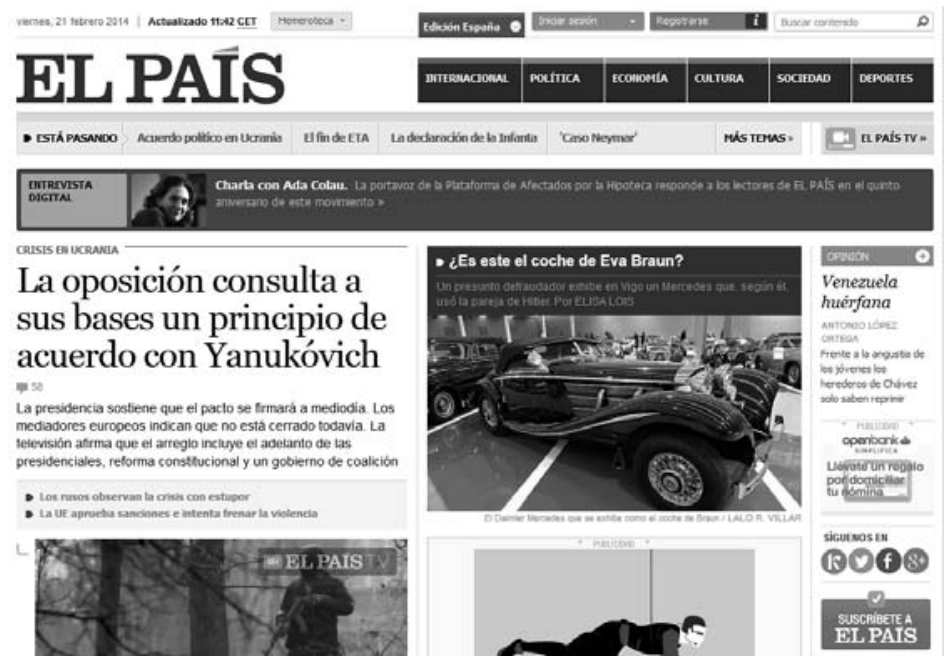

Imagen 1. Uso residual de la entradilla. Fuente: El País, 21 de febrero de 2014

Entre los nuevos elementos destacan el "Como ti fa sentire questa notizia" en el Corriere della Sera y las secciones de titulares como "En continu" en Le Monde que ya aparece en la primera página y ofrece un conjunto de títulos de la última hora y que fueron comentadas al inicio del artículo.

Los titulares, en general, buscan un buen posicionamiento en los buscadores y una buena difusión a través de la red pero sin perder su identidad como elementos informativos y, en ocasiones, marca ideológica del periódico.

Los medios de comunicación digitales analizados priman la actualización casi al último segundo y la cantidad de información que puede recibir el lector con más de 100 titulares en la portada. La primera pantalla de Le Monde prácticamente está compuesta por diferentes elementos del titular y una fotografía. Como ejemplo de la relevancia de éste podemos tomar el 24 de febrero aparece en la parte superior la barra "En ce moment" con los indicativos: "ukraine, Sotchi 2014, Facebook, Municipales 2014, Thaïlande, Venezuela, Centrafrique, Syrie, Centenaire 14-18". A continuación la información sobre Ucrania con todos los elementos, salvo la fotografía que podrían ser considerados elementos del titular. "L'Ukraine, cette incomprise" como título. Como subtítulo: "Pas plus les Russes que les Occidentaux ne comprennent ce pays qui n'est ni l'Est ni l'Ouest, ou qui est les deux à la fois". Y otros que consideramos sumarios en este caso: "Le pouvoir ukrainien se réorganise et regarde vers 1'Europe"; "Ukraine: la folle journée où le pouvoir a basculé", "Ukraine: six questions sur l'aprèslanoukovitch"; "Loulia Timochenko, une ambietieuse revenante". En la derecha de la página, la sección "En continu" que es un conjunto de titulares.

La relevancia adquirida por este elemento se puede observar, además, en la creación de secciones dedicadas exclusivamente a incluir el título de varias noticias como en el caso de Le Monde ("En Continu") con presencia en la primera pantalla y que incluye exclusivamente titulares muy breves, entre 5 y 12 palabras, o en The Times en "Latest News", en ambos casos con títulos breves que suelen tener menos de 8 palabras. 
La importancia del titular se incrementa en los primeros momentos informativos de acontecimientos no previstos o no rutinarios, especialmente en el caso de catástrofes, sucesos inesperados o crisis políticas-sociales. En estas situaciones, el título utilizado suele ser informativo, cuando sitúa la acción y aporta los últimos elementos conocidos del hecho tratado. En este caso, la función del título, además de ofrecer información al lector y llamar su atención sobre la importancia del hecho que está ocurriendo en el mismo momento de la recepción, cobra especial importancia como indicador de que el medio de comunicación actualiza continuamente su información, está en el lugar del acontecimiento y se compromete a ofrecer los últimos avances del mismo casi cada minuto.

En otras ocasiones, el propio medio incitado por su política comunicativa y, concretamente, por su estrategia de titulación, opta por títulos indicativos que llaman la atención el lector sobre la importancia y actualidad del acontecimiento y lo reconducen a través de un enlace a la información, interpretación u opinión sobre el mismo.

Un caso de crisis vivido recientemente, la situación político-social en Ucrania permite ejemplificar esta situación en la que la titulación consigue uno de sus momentos álgidos en los cibermedios. El tratamiento más espectacular desde el punto de vista de la titulación fue el del medio francés Le Monde. Durante las horas más intensas de la crisis de Ucrania a través del cintillo "Live" y la indicación "La crise en Ukraine" (imagen 2) daba enlace a una ventana que conectaba directamente con las reacciones en twitter. De este modo, a través de titulares se intentaba transmitir la sensación de directo y dejar el rol del periodista mediador e intérprete de la noticia para momentos posteriores. Así se hizo el viernes 21 de febrero "Uneasy peace after all-night Ukraine talks" (The Times, 21 de febrero) o "Kiev, guerra in piazza" (Corriere della Sera, 21 de febrero) o al día siguiente en con títulos más informativos ("La oposición ucraniana asegura que Yanukóvich ha abandonado Kiev", El País, 22 de febrero) o más expresivos ("Niguém cantou vitória na praça da Independência", Jornal de noticias, 22 de febrero).

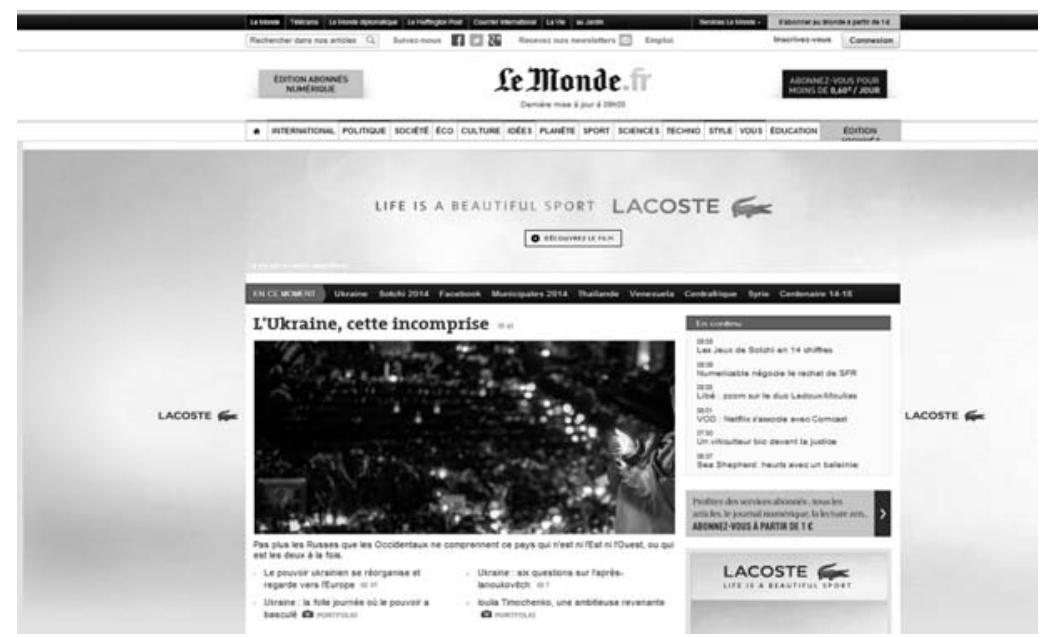

Imagen 2. Importancia del titular. Fuente: Le Monde, 24 de febrero de 2014 
Aunque se conservan todos los elementos indicados, el diseño y la tipografía tienden a ser cada vez más sencillos, buscando la eficacia comunicativa y evitando todo tipo de movimiento o llamadas al lector a través de efectos visuales. El diseño de los medios analizados es más o menos regular y estable que busca al lector a través del contenido. El titular conforma normalmente un hipervínculo que marca el itinerario de lectura del mismo a partir de los diferentes apartados de contenido de la información y, en otros casos, de elemento multimedia al que se dirige. Cuando se utilizan hipertextos tienen una función de anclaje on normalmente un enlace interno. Dentro de los diseños más innovadores podemos destacar la "multihipertextualidad" de los titulares de Corriere della Sera (imagen 3) que ofrecen diferentes enlaces dentro de un mismo título, en ocasiones con enlaces temáticos que dirigen al lector a contenidos propios del medio que desarrollan la noticia y, en otras, con títulos múltiples que ofrecen elementos multimedia que complementan la noticia. Titulares compuestos con dos enlaces diferentes. Por ejemplo, El Corriere della Sera del 21 de febrero 2014 (edición tarde) presenta el siguiente titular: "Renzi é al Quirinale, governo al via Alfano più vice, resta all'Interno All'Economia ci va Padoan/ I nomi". "Il Nomi" aparece en rojo y subrayado y lleva a un enlace que complementa y documenta la noticia diferente al resto del titular.

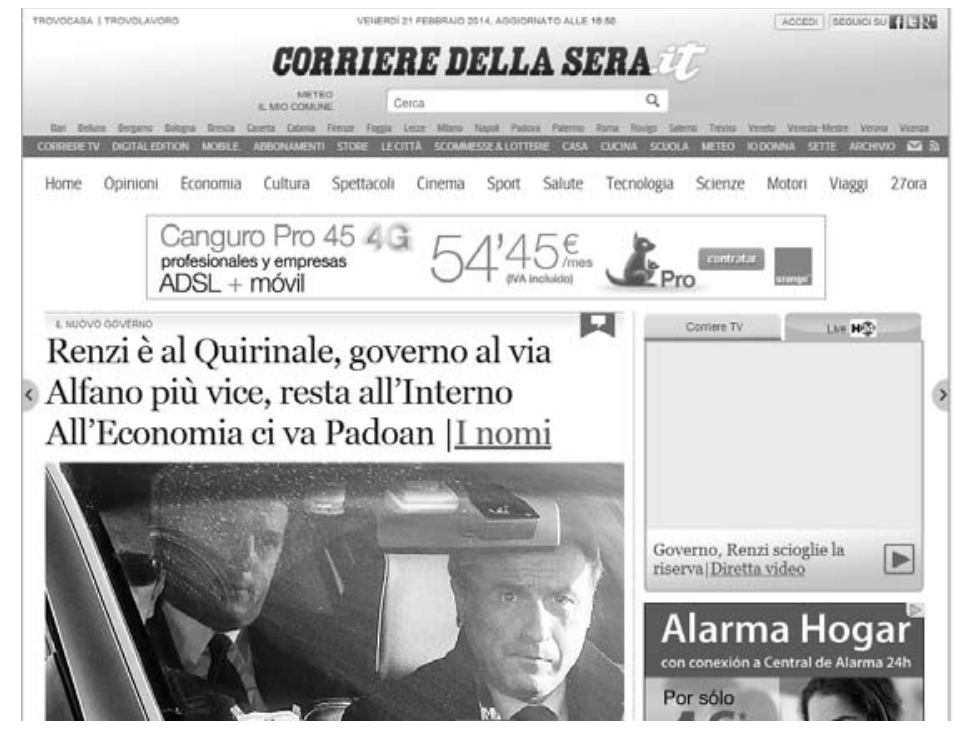

Imagen 3. Nuevos diseños de titulares. Fuente: Corriere della Sera, 21 de febrero de 2014

En muchas ocasiones los subtítulos no llevan a otra información sino que complementan el texto principal del titular con un elemento multimedia. En esta ocasión, el titular suele describir brevemente el contenido de los imágenes o audios. Puede ser de dos tipos: a) Informativo. E mentre Matteo sale al Quirinale i suoi "fuggono" a Miami/Le Immagini ("Le Immagini" aparece subrayado y en rojo); o b) Apelativo cuando llama al lector a algún tipo de acción. Fassino si cimenta con l'inglese, ironie 
in Rete. Guarda il video (Corriere della Sera, 21 de febrero 2014 tarde) (En rojo y subrayado "Guarda il video").

En general, todos los elementos del titular se reinventan dentro de la estructura hipertextual convirtiéndose en un espacio de subrayado de información relevante pero, sobre todo, en un enlace.

\section{Conclusiones}

Los titulares en los cibermedios europeos analizados incrementan paulatinamente su importancia como transmisores de la última hora de las noticias de portada, indicadores hipertextuales de las diferentes propuestas de lectura interiores que se ofrecen al lector y, sobre todo, como elementos de archivo y de posicionamiento web en las páginas de la noticia. La diversificación de los roles tradicionales de resumir y atraer al lector hacia la noticia, se consigue en los diarios digitales a través de una adaptación a las características de la web que provocan modificaciones en los diferentes elementos del titular y en las estrategias de titulación de los periodistas.

En relación con las hipótesis de las que partía la investigación, se puede deducir que el titular incrementa su presencia y relevancia en las portadas de los ciberdiarios europeos, especialmente en momento de crisis y de informaciones de "último segundo". Se registra una tendencia a una menor adaptación de los titulares de portada a la red que en las páginas interiores, aunque en muchas ocasiones se repite sobre todo en la noticia principal en la que prima la "última hora".

Como se ha indicado, en la mayoría de los casos, la función principal del titular continúa siendo informativa, aunque se asumen otras propias de la red como la transmisión a terminales móviles, la personalización de la información o el fácil acceso del lector a través de los buscadores. Y, finalmente, la tendencia a la claridad y nitidez en los diseños de las portadas provoca la eliminación de algunos de los elementos que la titulación ha ido sumando en las últimas décadas con el fin de responder a las nuevas funciones y responsabilidades que se le iban adjudicando pero, al mismo tiempo, adquiere otras nuevas $y$, en algunos casos, se convierte incluso en una nueva sección del medio.

La adaptación de los titulares a los cibermedios es paulatina y asume en cada media experiencia diferente en función del contexto y de las estrategias comunicativas y de titulación. Sin embargo, la asunción de nuevos roles y la descontextualización del titular provocada por la lectura del mismo a través de diferentes dispositivos y contextos diferentes al de la portada original para el que fue pensado, provocan mutaciones necesarias que le permitan conservar su esencia. Las tendencias detectadas en el momento actual se resumen en el siguiente decálogo:

1. Relevancia creciente. Los títulos adquieren gran importancia en las portadas de los diarios digitales especialmente para transmitir en directo acontecimientos inesperados como la reciente crisis en Ucrania.

2. Nuevas funciones. El titular en los cibermedios cumple, además de las tradicionales, otras tres funciones externas al contexto informativo en el que se ubica: a) facilitar su localización a través de los buscadores digitales; b) diseñar un itinerario hipertextual que facilite e incite a la lectura personalizada de aquellos aspectos del 
texto que pueda interesar a cada uno de los receptores y c) favorecer un buen posicionamiento de la información en la red.

3. Viejos elementos para nuevos roles. Para asumir los nuevos roles, contenido y forma del titular se adaptan a la red. Los elementos tradicionales de la titulación en los medio impresos se adaptan a las nuevas necesidades de la red. El título centra el protagonismo en la portada, quedando libre en muchas ocasiones del antetítulo y de los sumarios.

4. Recuperados los cintillos. Adquieren cada vez mayor importancia los subtítulos y el cintillo como elemento hipertextual y, residualmente el ladillo en el desarrollo de las noticias.

5. Pese a todas las adaptaciones, el titular conserva su función principal como principal elemento informativo de la noticia para lo que debe tener sentido en sí mismo y ser concreto, inequívoco y sugerente.

6. Creación de espacios y secciones. Los periódicos europeos comienzan a incluir elementos nuevos en el titular relacionados, sobre todo, con la interactividad. Es el caso de "Como ti fa sentire questa notizia" (Corriere della Sera) o secciones como "En continu" (Le Monde).

7. Estrategia SEO. La estrategia de titulares tiene en cuenta el posicionamiento en web como uno de los principales objetivos de la misma incluyendo palabras clave sobre todo al principio del titular.

8. Nuevos formatos. Pese a que desde un inicio los titulares en los cibermedios fueron enlaces, en el momento actual se experimenta con nuevas formas hipertextuales como los que incluyen más de un enlace o los desplegables que añaden más información.

9. Incremento cuantitativo. La necesidad de actualización y de atraer lectores hacia la web del medio, provocaron la multiplicación de titulares de primera página.

10. Adaptación a las redes sociales. Los titulares tienen en cuenta su distribución a través de redes sociales e intentan adaptarse a sus necesidades con el fin de conseguir una buena jerarquización y óptima difusión en la red.

\section{Referencias bibliográficas}

ALARCOS LLORACH, Emilio (1997): "El lenguaje de los titulares", en LÁZARO CARRETER, Fernando: Lenguaje en Periodismo escrito. Madrid, Fundación Juan March.

BERNAL TRIVIÑO, Ana Isabel (2012): "Consumo de noticias durante la campaña electoral del $20 \mathrm{~N}$ en la prensa online española". Congreso Internacional en Comunicación Política y Estrategias de Campaña, Instituto Universitario de Investigación Ortega y Gasset (Madrid).

CASASÚS, Josep María (1988): El periodisme a Catalunya. Barcelona, Plaza\&Janes.

DÍAZ NOCI, Javier (2002): La escritura digital: hipertexto y construcción del discurso informativo en el periodismo electrónico. Bilbao, Servicio Editorial de la Universidad del País Vasco. 
DÍAZ NOCI, Javier (2010): "Medios de comunicación en internet: algunas tendencias", En El profesional de la información, v. 19, n. 6, noviembre-diciembre, pp. 561-567.

EDO, Concha (2003): Periodismo Informativo e interpretativo. El impacto de Internet en la noticia, las fuentes y los géneros. Sevilla, Comunicación Social.

FONTCUBERTA, Mar de (1993): La noticia. Pistas para percibir el mundo. Barcelona, Paidós.

GÓMEZ MOMPART, Josep Lluís (1982): Los titulares en prensa. Barcelona, Mitre.

GOMIS, Lorenzo (1991): Teoría del periodismo. Cómo se forma el presente. Barcelona, Paidós.

LARA CID, Daniel Alejandro (2011): Estudio morfosintáctico contrastivo de titulares de periódicos en inglés y en español. Temuco, Tesina presentada a la Escuela de Lenguas y Traducción de la Universidad Católica de Temuco.

LÓPEZ HIDALGO, Antonio (2001): El titular. Manual de titulación periodística. Sevilla, Comunicación Social.

MASIP, Pere et al (2010): "Investigación internacional sobre ciberperiodismo: hipertexto, interactividad, multimedia y convergencia", en El profesional de la información, vol. 19, n. 6, noviembre-diciembre, pp. 568-576.

ODRIOZOLA CHÉNÉ, Javier (2012): “Análisis de contenido de los cibermedios generalistas españoles. Características y adscripción temática de las noticias principales de portada". Comunicacion y Sociedad, Universiad de Navarra, XXV, Núm. 2, pp. 279-304.

PALAU SAMPIO, Dolors (2013): "La actualidad decantada. Enfoques y estilos en los titulares de portada". Estudios sobre el mensaje periodístico, vol. 19, núm. 2, pp. 825-839. Madrid, Servicio de Publicaciones de la Editorial Complutense.

POU AMÉRIGO, María José (2001): "Los titulares de prensa y los nuevos servicios de información por correo electrónico y teléfono móvil". Estudios sobre el mensaje periodístico, $\mathrm{n}^{\circ}$ 7. Madrid, Servicio de Publicaciones de la Editorial Complutense.

SALAVERRÍA, Ramón (2005): Cibermedios. El impacto de internet en los medios de comunicación en España. Sevilla, Comunicación Social.

ZORRILLA BARROSO, José Manuel (1996): El titular de la noticia. Estudio de los titulares informativos en los diarios de difusión nacional. Madrid, tesis defendida en la Universidad Complutense. 